\title{
Papers
}

\section{Mapping choice in the NHS: cross sectional study of routinely collected data}

Mike Damiani, Carol Propper, Jennifer Dixon

\begin{abstract}
Objective To identify where in England there are likely to be most constraints on choice of hospital for patients waiting longer than six months for elective care.

Design Cross sectional study using routinely collected data. Setting Population of England and NHS trusts and private sector hospitals in England.

Participants All residents in England.

Main outcome measures Availability of beds (available and unoccupied hospital beds), demand (number of people waiting longer than six months), and access (travel time to facilities) to hospital care in England.

Results Most people in England already have an extensive potential choice of hospital. The number of available and unoccupied beds within 60 minutes' travel time was lowest in the Scottish borders, North Yorkshire, and parts of East Anglia, Lincolnshire, Devon, and Cornwall. This pattern was not altered by adding in private facilities. Putting demand with this supply, the number of people in a geographical area waiting longer than six months per bed within 60 minutes' travel time was highest in the south east (except London), parts of the south west (Cornwall, Bristol), East Anglia, and the Welsh border.

Conclusion People in the south east (outside London), East Anglia, and parts of the south west are likely to have to travel further to exercise meaningful choice of hospital for elective care.
\end{abstract}

\section{Introduction}

One aim of the UK government is to introduce more choice into the NHS in England. Several key policies exist on this theme. The supply of providers (public and private) in secondary, particularly elective, care and primary care is being boosted. For example, 30 new diagnostic and treatment centres are now open and a further 15 are planned as of December $2004 .^{1}$ Competition, or at least contestability, among secondary care providers is being enhanced. ${ }^{2}$ The choice of secondary care provider for patients waiting more than six months for elective care is to be extended, and a national consultation exercise on choice has taken place. ${ }^{3}$ These changes are underpinned by a new system-essentially a cost per case mechanism - of financial flows around the NHS. ${ }^{4}$

Increasing patient choice of provider is integral to these policies. ${ }^{3}$ Since 2002, two groups of patients-those waiting longer than six months for cardiac surgery, and those in London waiting longer than six months for treatment in selected specialties-have been offered a choice of provider that can supply treatment more quickly. Early results show that choice seems popular-for example, over $70 \%$ of 5000 patients involved in pilot schemes in London chose to be treated by another provider. A MORI poll for the BMA showed that if faced with a long wait $27 \%$ of people would travel anywhere in the United Kingdom for treatment by the NHS. ${ }^{5}$ The government expanded the model for choice to all patients waiting longer than six months for treatment across all specialties by August 2004, with more choice to be offered in the future.

Choice encompasses several dimensions. The current policy focuses on choice as a means of decreasing waiting times, but patients are also concerned about other dimensions of care, in particular quality. ${ }^{6}$ Regardless of dimension, expanding choice of provider to patients is a challenge to systems such as the NHS in which supplies are limited. We focused on the time it would take patients to travel to a provider. We used routinely collected data to examine the extent to which travel time would increase choice given the existing pattern of NHS and private facilities, ignoring differences in quality. If patients are to be given a choice of provider, are there differences in the time those seeking care will have to travel? If so, where in the country will people have to travel furthest to exercise this choice? Will increased use of private facilities, in addition to those in the NHS, change the amount of time people will have to travel?

\section{Methods}

Focusing on England, we used routine data available to the NHS and the private sector to construct maps showing the location of available NHS and private beds for elective care and their accessibility to patients, measured as time taken to travel to the facilities. Firstly, we calculated travel time from where patients lived-their census electoral ward-then we added in current demand for these facilities, as measured by number of patients waiting for a bed. This is relative to travel time and provides a measure of the extent of possible choice of location that patients have, based on current patterns of supply and referrals. We determined where in the country there were likely to be most constraints on patients for choice of provider. Travel time was chosen as the unit of analysis rather than administrative or geographical units, because this perspective is more relevant for patients.

\section{Data sources}

From the Department of Health website we downloaded data by NHS trust on the number of general and acute beds open and available at March 2002. ${ }^{7}$ We calculated the number of available unoccupied beds (potential spare capacity) from data on the number of available and occupied general and acute beds.

We obtained data on the number of beds in private (non-NHS) hospitals and private facilities in NHS trusts as of 


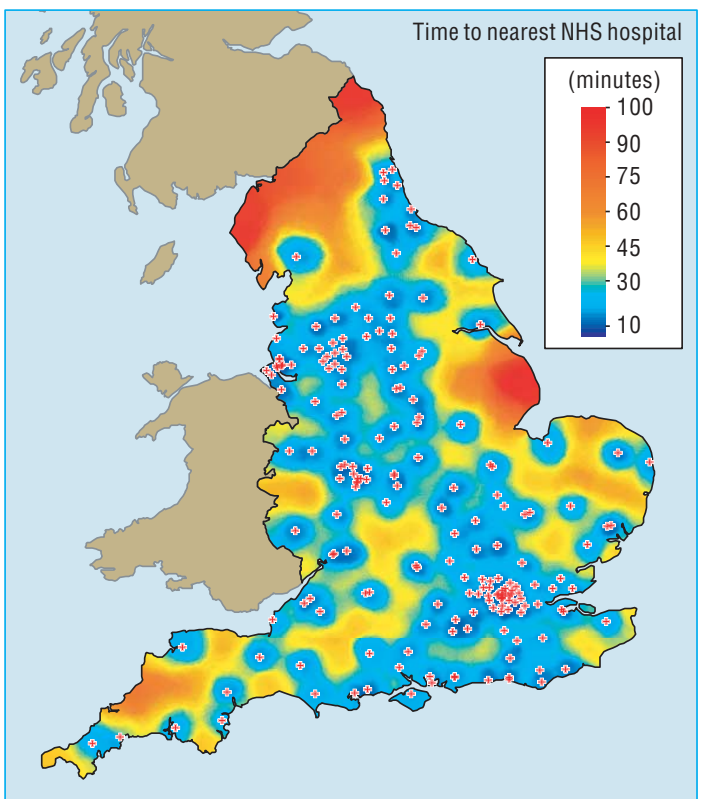

Fig 1 Travel time (gradation of colour) to nearest NHS trust dealing with acute conditions, England, 2001

$2001 .^{8-10}$ Only private facilities that provided care in medical and surgical specialties were included. We excluded facilities that provided other services exclusively (for example, rehabilitation after addiction, care for patients with mental illness, and termination of pregnancy). As data were not available on the number of available and occupied beds per private facility, we estimated bed occupancy at $60 \%$ as historically this is the level of occupancy experienced by the UK private sector. ${ }^{8}$ Therefore, we estimated the number of available and unoccupied non-NHS beds as $40 \%$ of the total number of beds.

From the Department of Health's Organisational Codes Service we obtained the postcodes of all NHS trusts dealing with acute conditions. ${ }^{11}$ The postcodes of private facilities were taken from published directories. ${ }^{8-10}$ From the Department of Health website we obtained for the last quarter of 2001-2 the number of patients in each NHS trust waiting longer than six months for inpatient care. ${ }^{12}$

\section{Mapping data and calculating travel times}

By importing the postcodes of these facilities into MapInfo ${ }^{13}$ we produced a map showing the location of private hospitals and NHS trusts dealing with acute conditions. Using Microsoft MapPoint ${ }^{14}$ we calculated the travel time to these facilities and the travel times and distances between hospitals and the centroids of electoral wards or between hospitals and the centroids of local authority districts. We adjusted travel times to reflect the average speed of cars across England, and we verified a selection of speeds against several websites. ${ }^{14-17}$ Using data from the 1991 census (using enumeration district boundaries), we constructed boundaries for local authority districts and electoral wards. ${ }^{18} \mathrm{We}$ calculated travel time from the centroid of each electoral ward in England to the centroid of the electoral ward containing the main postcode of each NHS trust or private facility. When travel time exceeded 60 minutes, we calculated the travel time from the centroid of the local authority district to the centroid of the electoral ward containing the main postcode of each NHS trust or private facility. In this way we identified the number of facilities (hospitals and beds) accessible within specified travel times for patients in England.
Using population data for each electoral ward from the 2001 census, we calculated the number of people, or the proportion of the population of England, that theoretically had access to NHS or private facilities within certain travel times. When boundaries had changed since 1991, we adjusted the population data for 2001 accordingly.

For all NHS trusts we identified the number of patients waiting longer than six months for elective care. We calculated the number of patients waiting per available and unoccupied bed for all NHS trusts within 60 minutes' travel time of each electoral ward in England. The number of patients waiting is not the same as demand; it is an indicator of the number of people already waiting for care and so reflects the amount of competition a patient faces for a given supply of beds. These data thus provided estimates of the demand for care relative to the available and accessible spare capacity. The resulting maps were generated using MapInfo and Vertical Mapper (www.mapinfo.co.uk).

\section{Results}

Figure 1 shows the location of each NHS trust dealing with acute conditions in England. For most areas of England, an acute NHS trust was accessible within 100 minutes' travel time, and for large parts of the country a NHS trust was accessible within 30 minutes. Overall, $25 \%$ of the population had one hospital within 15 minutes' travel time and $41 \%$ had up to two hospitals. Fifteen per cent had no hospital within 30 minutes' travel time, but $98 \%$ had one hospital and 92\% had two hospitals within 60 minutes' travel time.

In three areas of England people have to travel relatively further to reach an acute NHS trust: the north of England close to the border with Scotland, East Anglia and parts of Lincolnshire, and parts of Devon and Cornwall.

The map did not adjust for population density, and so demand. To the extent that long travel times reflected low population densities, then some of the long travel times affected relatively fewer people.

Figure 2 shows the number of NHS trusts within 60 minutes' travel time. We found that areas with high and low access to

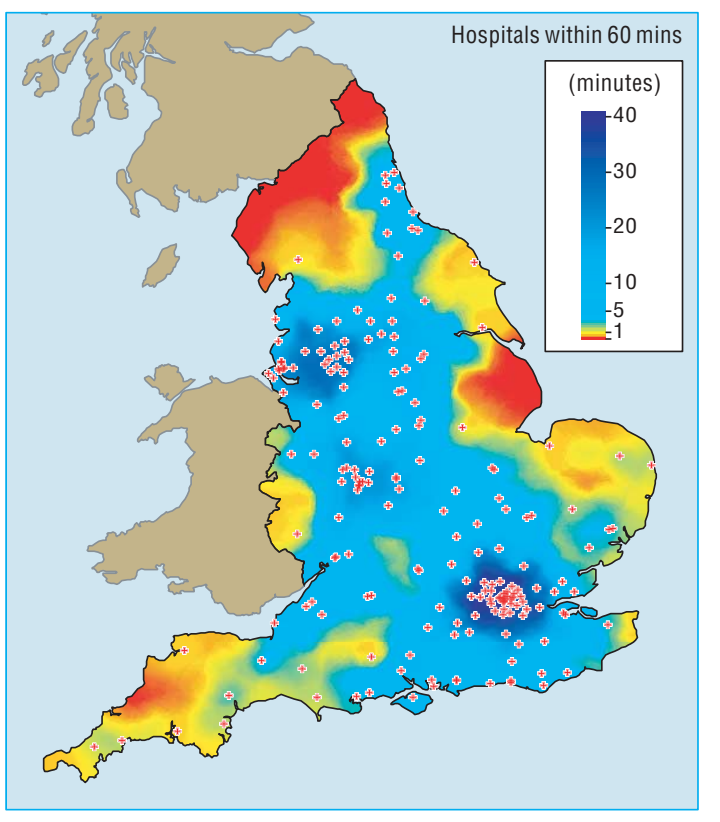

Fig 2 Number of NHS trusts within 60 minutes' travel time, England, 2001 


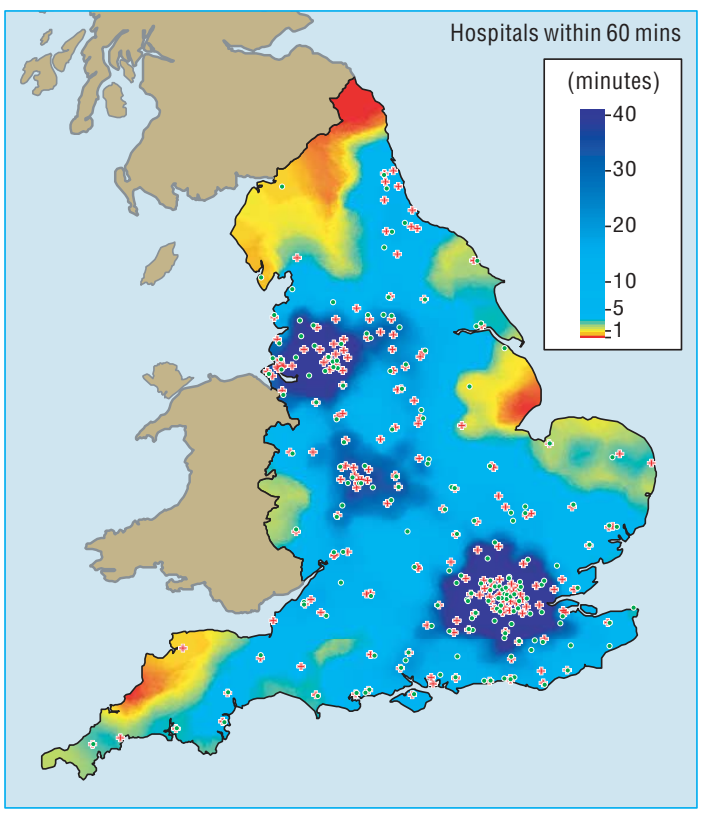

Fig 3 Number of NHS trusts and private facilities within 60 minutes' travel time, England, 2001

hospitals were relatively similar when we considered 30 minutes' travel time instead of 60 minutes. The longer the travel time we considered, the greater the blurring of boundaries between areas of low and high access. As 60 minutes is reasonably long for a one way journey, we used this time for the rest of the analysis.

Most people in England have access to at least one trust within 60 minutes' travel time. Areas with least choice of supply were the Scottish and Welsh borders and parts of East Anglia, Lincolnshire, and the south west. When considering choice in the Welsh borders we did not account for facilities in Wales.

Figure 3 shows travel time when private facilities are taken into account. This map is similar to figure 2, except the number of facilities within 60 minutes' travel time has increased, particularly in areas of relatively low supply. The proportion of the population with access to NHS and private facilities within 60 minutes' travel time was only $1 \%$ higher than the proportion with access to the NHS alone, however, because of the relatively small number of private facilities and because most are located near NHS facilities.

Hospitals vary in size, so the pattern of potentially available beds may differ. Figure 4 shows the number of available and unoccupied NHS beds within 60 minutes' travel time in England in 2001. Access to these beds resembles the pattern of access to facilities shown in figure 2. Within 60 minutes' travel time, $98 \%$ of people in England have access to up to 100 unoccupied NHS beds and $76 \%$ have access to up to 500 unoccupied NHS beds. The number of available and unoccupied NHS and private beds within 60 minutes' travel time is almost identical to that depicted in figure 4, due to the relative paucity of private beds (data not shown). People in England therefore have a large potential for choice of provider, with most people having access to a bed within 60 minutes' travel time.

Our maps do not account for demand. Figure 5 shows demand relative to supply. We chose as a measure of the potential for choice, the number of patients waiting longer than six months for elective inpatient care per available and unoccupied NHS bed within 60 minutes' travel time.

The demand per unoccupied bed was greatest not only in some of the areas of low supply-parts of East Anglia, the area

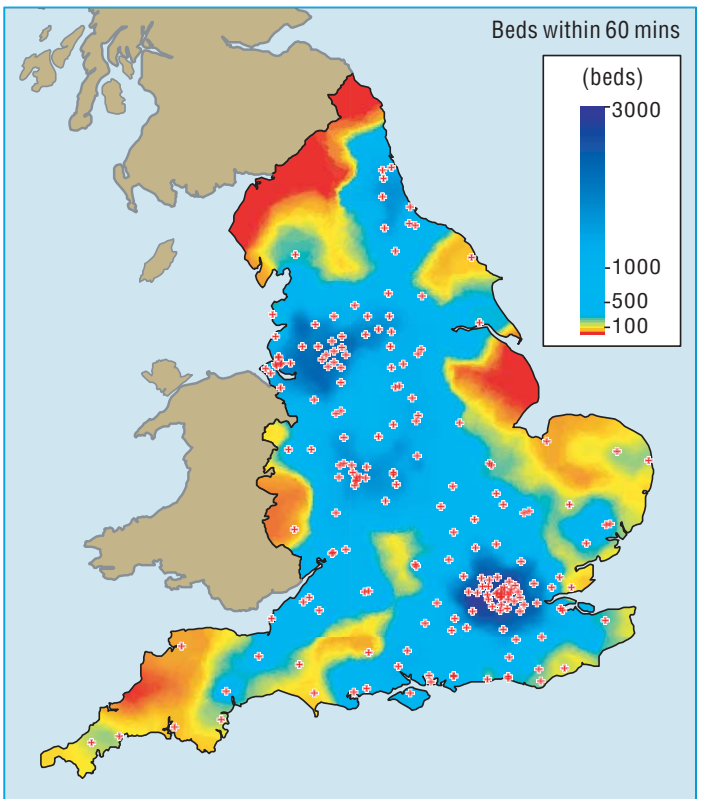

Fig 4 Number of available and unoccupied NHS beds within 60 minutes' travel time, England, 2001

near the Welsh border, part of Cornwall-but also in areas of relatively high supply - the south east except for London, and south of Bristol. In contrast, other low supply areas (for example, the Scottish borders) also had low demand, so demand relative to supply was low and the potential for choice was high.

Adding in the number of available and unoccupied beds in the private sector (fig 6), shows the effective competition for available and unoccupied beds in different parts of the country.

The pattern was similar to that without private beds. The areas with high competition for beds were concentrated in the south east, particularly outside London, parts of the south west (Cornwall, Bristol), East Anglia, and an area alongside the Welsh

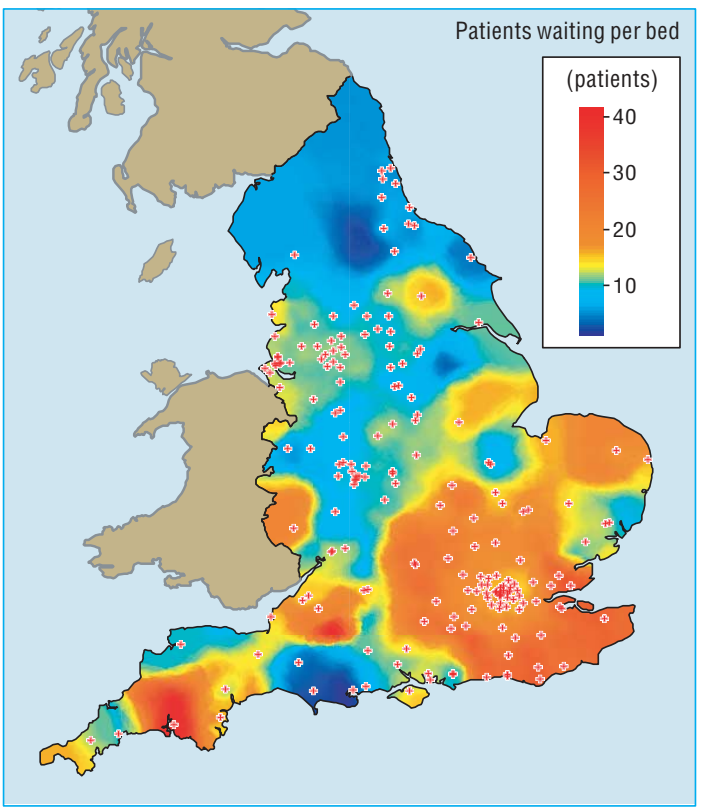

Fig 5 Number of patients waiting longer than six months for elective inpatient care per available and unoccupied NHS bed within 60 minutes' travel time 


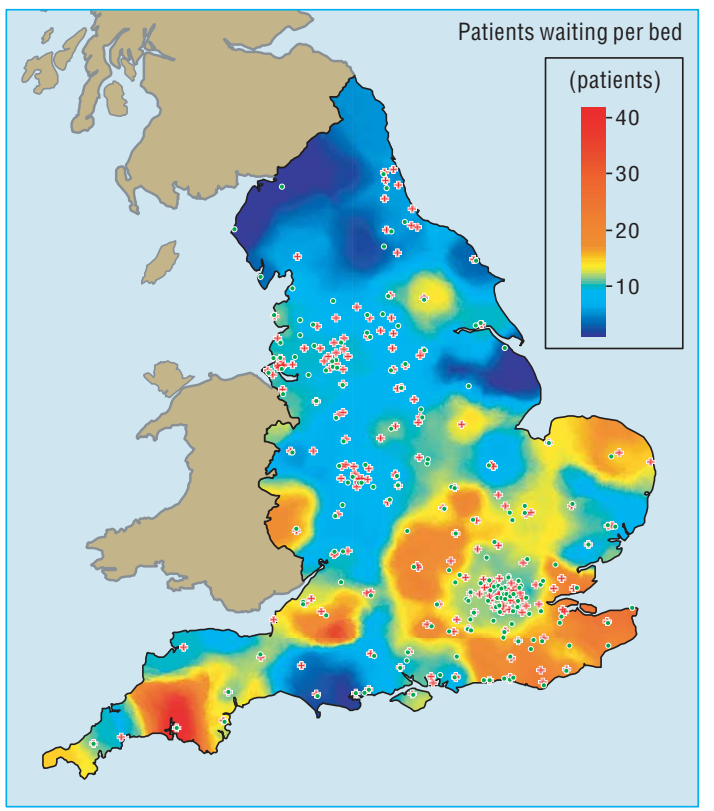

Fig 6 Number of patients waiting longer than six months for elective inpatient care per available and unoccupied NHS bed, and private beds within 60 minutes' travel time

border. People in these areas need to travel further than those living in other areas of England to access available beds.

\section{Discussion}

For most people in England there is large potential for choice of hospital for elective care. Almost all have access to an NHS trust within an hour's travel time, and over $90 \%$ have the choice of two NHS providers. This echoes research from the 1990s, which found that hospital location was such that competition between hospitals was possible for large areas of England. ${ }^{19}{ }^{20}$ Areas with the lowest number of NHS trusts within an hour's travel include the Scottish borders, North Yorkshire and parts of Lincolnshire and East Anglia, and Devon and Cornwall. These are also the areas with lowest access to available and unoccupied NHS beds. When private facilities were considered access improved to hospitals in most of these areas, except the north east of England, south Lincolnshire, and north Cornwall. But this finding is misleading, as access to beds is not improved because of the small number of beds in private facilities. If a large number of NHS patients are to exercise choice of hospital then choice of existing NHS facilities rather than private facilities needs to be expanded.

The pattern changes when the demand for as well as supply of beds is considered. The areas of low choice include most of the south east (outside London) stretching to the south coast, East Anglia, an area south of Bristol, and Cornwall. This stems from at least two sources: in East Anglia and Cornwall it seems that a lack of available beds drives the lack of choice, whereas in the south east a relatively large number of patients is already awaiting treatment. Private beds alleviate some of this demand on NHS facilities in London and surrounding areas.

\section{Limitations of study}

Our study has several limitations. We focused on only travel as one aspect of choice, whereas patients are concerned about several factors, such as quality, which would affect choice. Travel time refers to use of car only, whereas patients may not choose, or be able to use, this form of transport. We chose to study a maximum (one way) travel time of 60 minutes for elective care. Patients might have treatment on a day case basis or they may have a longer stay and desire visits from relatives and friends. In these cases a maximum one way travel time of two hours a day seemed reasonable for patients receiving elective care. We examined the sensitivity of our results, using this assumption. As travel time is lengthened, the number of hospitals and beds a patient can access increases. Only $25 \%$ of people have access to more than one hospital within 15 minutes' travel time. Comparable proportions for travel times of 30,60, and 90 minutes are $68 \%$, $95 \%$, and slightly less than $100 \%$. The choice of 60 minutes blurs some of the differences between areas that would be accessible if a shorter travel time was chosen. As it is not known for how long most patients would be prepared to travel, the use of this time makes the estimated differences in choice less stark between areas.

Travel time is also only one measure of accessibility; other measures that are important to patients include the cost of travel and the availability of public transport. Public transport may reduce or increase the travel time, resulting in an overestimation or underestimation of the travel times in our study. It was not possible to take these factors into account as we used secondary sources of data.

To measure spare capacity by acute providers we used the number of available and unoccupied beds classified only as general or acute. This value was calculated from a census of beds at one time point and therefore the number will fluctuate. Other factors for supply are also relevant, such as the number of available staff (and the ratio of staff to patients) and the availability of operating theatres to carry out elective procedures. An assumption implicit in our analysis is that every available and unoccupied bed could be staffed to treat increased demand from patients waiting longer than six months who exercised choice from elsewhere in the country. Another assumption is that these beds would be available for elective care, whereas in reality patients admitted as emergencies would compete for those beds. It is not possible to estimate from routine data sources the actual number of beds available for elective care. We also cannot assign beds to specialities with any confidence. For these reasons we may have overestimated the extent of choice of provider and underestimated the time patients would need to travel to access spare capacity. However, if bringing into use such spare capacity incurred the same costs everywhere, the relative rankings of areas presented here would not change. Finally, if it is easier to bring spare capacity into use in the private sector rather than the public sector, our analysis would underestimate the contribution of the private sector to choice.

We chose number of patients waiting longer than six months for elective care at each NHS trust as an indicator of potential demand for beds. Waiting times are stock measures, and as such are affected by other factors of supply as well as demand, such as hospital inefficiency or the quality of care provided. Waiting times are therefore not a measure of demand alone. A system wide analysis showed that the response of demand in the NHS to decreases in waiting times was small, suggesting that waiting times are not a poor measure of demand. ${ }^{21}$ In addition, in a system such as the NHS in which care is, among other methods, rationed by waiting lists, the greater the number of people waiting for care at any particular NHS trust, the greater is the competition for a bed at that trust. We did not adjust for differences in efficiency between providers, as this is part of the reason why choice may be limited.

We have assumed implicitly that all specialties contribute equally to waiting list figures, but the distribution of waits may be 


\section{What is already known on this topic}

Patients are interested in exercising choice of provider for elective care

The NHS has a large potential for such choice

Patients are willing to travel to exercise their choice

\section{What this study adds}

In England, patients living in the south east (except London), East Anglia, an area south of Bristol, and Cornwall have the lowest choice of provider for elective care

Subsidising travel for people located in these areas may make choice of provider more attractive

Currently the supply of acute beds in non-NHS facilities is too small to make an important contribution to patient choice

uneven. ${ }^{22}$ This needs further investigation. Finally, waiting times pertain to NHS trusts rather than to local areas: our analysis assumes that this difference is not important.

\section{Implications for policy}

Patients in England who want to exercise choice of provider have varied distances to travel. Thus the costs of exercising such choice will vary. One way to overcome difference in costs would be to subsidise travel for patients requiring longer journeys. These patients are located in specific areas.

But travel time may not be the only barrier to choice. Patients in pilot studies have expressed an interest in receiving care from alternative providers, but a recent survey showed that $73 \%$ of 44710 patients in England who were referred from primary care were not given a choice of hospital or specialist. ${ }^{23}$ Expanding choice may require altering referral patterns in primary care. This, in turn, would require better information for the referrersfor example, the quality and capacity of services available. But even with this information, it would seem that patients in some areas have further to travel to exercise this choice.

Finally, new capacity (or measures to use existing capacity better) needs to be focused on the areas surrounding London, on East Anglia, and on Devon and Cornwall. These are not the areas in which diagnostic and treatment centres are to be located, thus given the current patterns for referral and capacity these facilities may do little to increase choice.

\section{Conclusion}

To our knowledge this is the first study to analyse both demand for, and supply of, NHS hospital facilities using patient travel time. Our analysis shows that individuals living in the south east outside London have less scope for choice of provider than those living in other parts of England.

Contributors: JD and CP conceived the study. All, in particular MD, developed the methods. MD was responsible for the analysis and producing the maps. JD and CP wrote the article. MD commented critically on the paper. CP revised the paper in the light of reviewers' comments. All authors are guarantors.

\section{Funding: None.}

Competing interests: None declared.

Ethical approval: Not required.

1 NHS Modernisation Agency. Treatment centres. 2003. www.modern.nhs.uk/scripts/ defaultasp?site id $=31$ (accessed 4 Jan 2005).

2 Dixon J, Le Grand J, Smith P. Can market forces be used for good? London: King's Fund, Dixon

3 HM Government. The NHS improvement plan. Putting people at the heart of public services. London: Stationery Office, 2004. www.dh.gov.uk/assetRoot/04/08/45/23/04084523.pdf (accessed 2 Jul 2004).

4 Department of Health. Reforming NHS financial flows: introducing payment by results. London: DoH, 2002. www.dh.gov.uk/assetRoot/04/06/04/76/04060476.pdf (accessed 25 Jan 2005).

5 Mori poll for BMA finds many patients willing to travel abroad for treatment. Press release archive, Jun 2002. www.mori.com/polls/2002/bma-travel.shtml (accessed 7 Jan 2005).

6 Appleby J, Harrison A, Devlin N. What is the real cost of more patient choice? London: King's Fund, 2003.

7 www.performance.doh.gov.uk/hospitalactivityindex.htm (accessed 7 Jan 2005).

8 Laing's healthcare market review 2001-2. London: Laing and Buisson, 2002.

9 Dr Foster good hospital guide 2002. London: Vermilion, Ebury, 2002.

10 Directory of independent hospitals and health services 1998/1999. London: Financial Times Health Care, 1999

11 National Administrative Codes Service. www.nhs.uk/nacs/ (accessed 7 Jan 2005).

12 Department of Health. Performance. 2005. www.dh.gov.uk/PolicyAndGuidance/ Performance/fs/en (accessed 7 Jan 2005).

13 MapInfo. www.mapinfo.com (accessed 28 Jan 2005).

13 MapInfo. www.mapinfo.com (accessed 28 Jan 2005).

14 Mappoint. www.mappoint.com (accessed 7 Jan 2005).

16 RAC. www.rac.co.uk/ (accessed 7 Jan 2005).

17 Automobile Association. www.theaa.com/ (accessed 7 Jan 2005).

18 Edina. UKborders. edina.ac.uk/ukborders/ (accessed 7 Jan 2005).

19 Propper C, Burgess S, Green K. Does competition between hospitals improve the quality of care? Hospital death rates and the NHS internal market. J Public Econ 2004:124782.

20 Propper C. Market structure and prices: the responses of hospitals in the UK National Health Service to competition. J Public Econ 1996;6:307-35.

21 Martin RM, Sterne JAC, Gunnell D, Ibrahim S, Davey Smith G, Frankel S. NHS waiting lists and evidence of national or local failure: analysis of health service data. BMJ lists and evidence
2003;326:188-98.

22 Martin S, Smith PC. Rationing by waiting lists: an empirical investigation.J Public Econ 1999;17:141-64

23 National Patients Survey Programme: 2003 results. Primary care trusts: patient survey 2003. www.chi.nhs.uk/eng/surveys/nps2003/pct.shtml (accessed 25 Jan 2005).

(Accepted 15 November 2004)

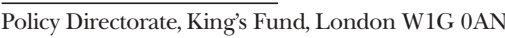

Mike Damiani visiting senior analyst

Jennifer Dixon director

Department of Economics, University of Bristol, Bristol BS8 ITH Carol Propper professor

Correspondence to: C Propper carol.propper@bristol.ac.uk

bmj.com 2005;330:284 